\title{
Translational activation by the noncoding RNA DsrA involves alternative RNase III processing in the rpoS 5'-leader
}

\author{
ARMIN RESCH, ${ }^{1,3}$ TARAS AFONYUSHKIN, ${ }^{1,3}$ TANIA B. LOMBO, ${ }^{1}$ KENNETH J. MCDOWALL, ${ }^{2}$ UDO BLÄSI, ${ }^{1}$ \\ and VLADIMIR R. KABERDIN ${ }^{1}$ \\ ${ }^{1}$ Max F. Perutz Laboratories, Department of Microbiology and Immunobiology, University Departments at the Vienna Biocenter, \\ A-1030 Vienna, Austria \\ ${ }^{2}$ Astbury Centre for Structural Molecular Biology, Faculty of Biological Sciences, University of Leeds, Leeds LS2 9JT, United Kingdom
}

\begin{abstract}
The intricate regulation of the Escherichia coli rpoS gene, which encodes the stationary phase sigma-factor $\sigma^{\mathrm{s}}$, includes translational activation by the noncoding RNA DsrA. We observed that the stability of rpoS mRNA, and concomitantly the concentration of $\sigma^{s}$, were significantly higher in an RNase III-deficient mutant. As no decay intermediates corresponding to the in vitro mapped RNase III cleavage site in the rpoS leader could be detected in vivo, the initial RNase III cleavage appears to be decisive for the observed rapid inactivation of rpoS mRNA. In contrast, we show that base-pairing of DsrA with the rpoS leader creates an alternative RNase III cleavage site within the rpoS/DsrA duplex. This study provides new insights into regulation by small regulatory RNAs in that the molecular function of DsrA not only facilitates ribosome loading on rpoS mRNA, but additionally involves an alternative processing of the target.
\end{abstract}

Keywords: DsrA; mRNA stability; noncoding RNA; rpoS

\section{INTRODUCTION}

In response to adverse environmental conditions, bacteria launch specific stress responses (Storz and Hengge-Aronis 2000). Several of these mechanisms are modulated by small noncoding RNAs (ncRNAs) (Gottesman 2005; Kaberdin and Bläsi 2006). Many ncRNAs exert their regulatory role by base-pairing with target mRNAs, thereby affecting their translation and stability (Massé et al. 2003a; Morita et al. 2006). In contrast to classical antisense RNAs, stress-related ncRNAs usually form imperfect duplexes with their targets and generally require the RNA chaperone Hfq (ValentinHansen et al. 2004) to facilitate mRNA/ncRNA interactions. Several ncRNAs, including DsrA and RprA, have been shown to affect expression of the rpoS gene encoding the stationary phase/stress sigma-factor, $\sigma^{\mathrm{S}}$ (Repoila et al.

\footnotetext{
${ }^{3}$ These authors equally contributed to this work.

Reprint requests to: Vladimir R. Kaberdin, Max F. Perutz Laboratories, Department of Microbiology and Immunobiology, University Departments at the Vienna Biocenter, Dr. Bohrgasse 9/4, A-1030 Vienna, Austria; e-mail: vladimir.kaberdin@univie.ac.at; fax: 43-1-4277-9546.

Article published online ahead of print. Article and publication date are at http://www.rnajournal.org/cgi/doi/10.1261/rna.603108.
}

2003). $\sigma^{\mathrm{S}}$ is known to control transcription of a large number of bacterial genes that have stress-protective functions during carbon starvation, temperature downshifts, and exposure to high osmolarity, acidic $\mathrm{pH}$, or denaturing reagents (Hengge-Aronis 2002a). The 5'-untranslated region of Escherichia coli rpoS mRNA forms a complex secondary structure, which results in weak accessibility of the ribosome binding site (rbs) and poor translation (Hengge-Aronis 2002b). Translation of rpoS mRNA can be activated by the ncRNA DsrA (Lease and Belfort 2000) through base-pairing with the rpoS leader, which leads to disruption of the inhibitory secondary structure (Lease and Woodson 2004).

The fate of intermediate ncRNA/mRNA complexes is still poorly understood. In E. coli, two RNase activities, RNase E and RNase III, have been implicated in decay of ncRNA/ mRNA complexes upon translational silencing (Kaberdin and Bläsi 2006). Morita et al. (2005) have put forward a model wherein an Hfq-RNase E-ncRNA complex is targeted to mRNA, which is consistent with the previously observed RNase E-dependent degradation of ncRNA targets (Massé et al. 2003a; Kawamoto et al. 2005; Vanderpool and Gottesman 2005). Although endonucleolytic RNase E 
cleavage sites created by structural rearrangements upon ncRNA/mRNA duplex formation (Geissmann and Touati 2004) can play a role in generation of primary decay intermediates (Afonyushkin et al. 2005), it remains to be seen whether a sole RNase E-based pathway is generally valid for any ncRNA/mRNA intermediate. Other studies suggested a role for the double-strand-specific RNase III in turnover of target mRNAs upon translational silencing by ncRNAs (Vogel et al. 2004; Afonyushkin et al. 2005; Huntzinger et al. 2005). Hence, cleavage by RNase III within the ncRNA/mRNA duplex and the resulting subsequent decay of the mRNA intermediate by the E. coli RNA decay machinery could rather resemble the RNAi scenario in eukaryotic organisms (Agrawal et al. 2003).

In contrast to the mechanisms leading to disassembly and processing of the intermediate ncRNA/mRNA complexes during ncRNA-mediated translational silencing, the molecular events that determined the fate of such intermediate complexes upon functional activation of target mRNAs have not been studied. Here, we used the DsrA-dependent activation of rpoS expression as a model system to address this question. Our data revealed a central role of E. coli RNase III in controlling rpoS mRNA turnover. We found that the ncRNA DsrA, besides its established role in rpoS translational activation, stabilizes the rpoS transcript by redirecting RNase III cleavage in its 5'-UTR.

\section{RESULTS AND DISCUSSION}

\section{RNase III affects rpoS mRNA stability and the level of RpoS}

With the aim to identify factor(s) affecting $r p o S$ regulation and stability, we tested for a possible role of RNase III in rpoS turnover. Northern blot analysis of total RNA isolated from an E. coli RNase III mutant strain revealed that the steady-state level and half-life of the full-length rpoS mRNA were increased when compared to the isogenic wildtype strain (Fig. 1). Correspondingly, the in vivo levels of $\sigma^{\mathrm{s}}$ were elevated in the $r n c$ mutant (Fig. 1A,B), thereby suggesting that RNase III is involved in the control of rpoS mRNA stability, and hence in regulation of the level of RpoS. In addition to the fulllength rpos mRNA, we could also detect a processing intermediate (Fig. 1A) likely formed upon RNase III cleavage at $G_{-112}$ (see below). The effect of RNase III inactivation on rpoS expression and stability was temperature-dependent and was more pronounced at $37^{\circ} \mathrm{C}$ when
A

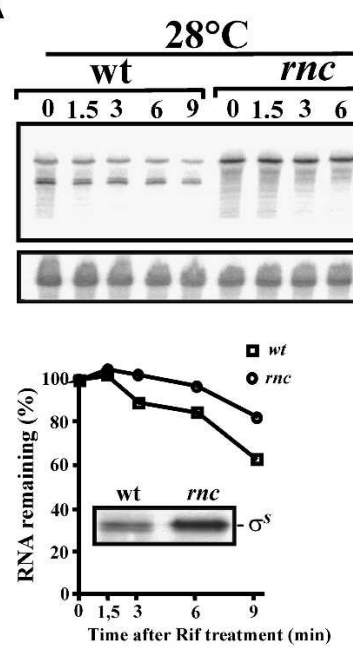

C

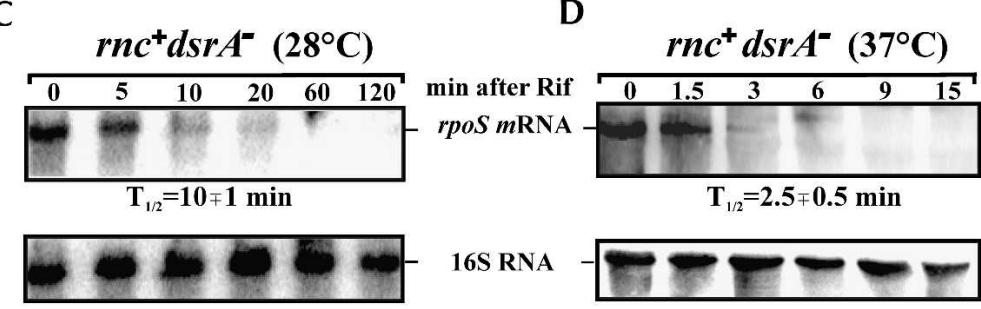

E

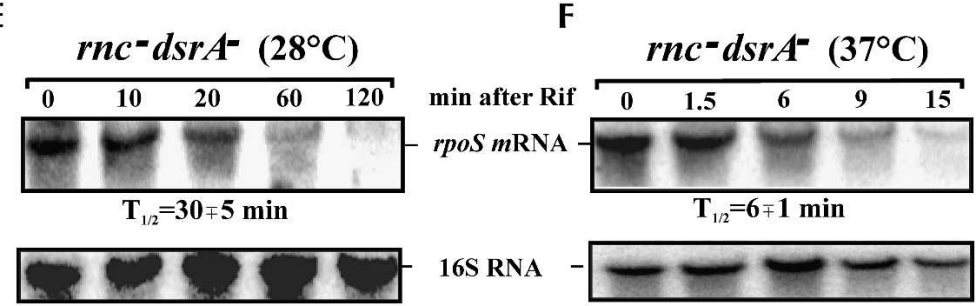

FIGURE 1. Effects of RNase III/DsrA inactivation on rpoS expression. The E. coli strain SDF204 (wt) and the isogenic RNase III $(r n c)$ deficient strain SDF205 as well as the $d s r A$ mutant $\left(r n c^{+} d s r A^{-}\right)$and its isogenic variant lacking functional RNase III $\left(r n c^{-} d s r A^{-}\right)$were grown to early log phase at $(A, C, E) 28^{\circ} \mathrm{C}$ and $(B, D, F) 37^{\circ} \mathrm{C}$, respectively. RNA samples were prepared from each culture before and after rifampicin treatment at the times indicated on top of the autoradiograph and further analyzed by Northern blotting. $(A, B)$ The corresponding graphs below show the relative amount of the full-length rpoS mRNA remaining at each time point as determined by PhosphorImaging and plotted as a function of time. The insets show the steady-state levels of $\sigma^{\mathrm{S}}$ determined by Western blotting in the wt strain and the isogenic $r n c$ mutant. The positions of $\sigma^{\mathrm{s}}, r p o S$ mRNA, and its RNase III-dependent processing intermediate $\left.{ }^{*}\right)$ are indicated. The half-lives of rpoS mRNA $\left(T_{1 / 2}\right)$ were calculated using the data obtained in independent experiments. 
compared to that at $28^{\circ} \mathrm{C}$ (Fig. 1). As the level of the ncRNA DsrA, one of the riboregulators stimulating rpoS translation, is known to be higher at $28^{\circ} \mathrm{C}$ than at $37^{\circ} \mathrm{C}$ (Sledjeski et al. 1996), our result suggested that the stabilizing effect of RNase III inactivation on rpoS mRNA is limited to mRNA molecules that are not involved in base-pairing with DsrA. Consistent with this idea, we observed a comparable half-life of rpoS mRNA in the wildtype strain and in the $d s r A^{-}$mutant (Fig. 1B,D) and, when compared to the $d s r A^{-}$strain (Fig. 1D), the stability of rpoS mRNA was found to be increased in the $r n c^{-}$ $d s r A^{-}$double-mutant strain (Fig. $1 \mathrm{~F}$ ) at $37^{\circ} \mathrm{C}$. The corresponding results were obtained with the isogenic strains at $28^{\circ} \mathrm{C}$ in the absence of DsrA (Fig. 1C,E).

\section{RNase III cleavage sites in the rpoS leader}

Next, we tested for RNase III cleavage sites in rpoS mRNA. RpoSII RNA (nucleotides -564 to +161 of rpoS mRNA) was incubated in the presence of increasing concentrations of RNase III, and the resulting products of cleavage were analyzed by primer extension. RNase III cleavage occurred with equal intensities within the double-stranded region of the rpoS leader at nucleotide positions -15 and -94 , respectively (Fig. 2A). It seems possible that RNase III cleavage at this position results in a rapid decay of the rpoS transcript. Consistent with this hypothesis, primer extension analysis of total E. coli RNA isolated from the wildtype strain and the RNase III mutant (Fig. 3A) revealed no RNase III cleavage intermediates, which would argue for their instability in vivo. Although we cannot exclude the formal possibility that RNA-binding proteins inhibit RNase III cleavage, we consider this as less likely, because of the differences in rpoS mRNA stability observed in the wildtype and RNase III mutant strains (see Fig. 1). Further support for the decisive role of RNase III cleavage at positions $-15 /-94$ in rpoS decay is provided by a recent mutational analysis of the Salmonella enterica rpoS leader. Mutations in stem II potentially interfering with RNase III cleavage were shown to increase expression of the corresponding rpoS-lacZ fusions (Brown and Elliott 1997; Jones et al. 2006). As the sequence of the three stem-loop structures (Fig. 2) including the mapped RNase III cleavage site upstream of the start codon is identical in E. coli and $S$. enterica, our results would suggest that the reported increase in expression of the mutant rpoS-lacZ fusions (Brown and Elliott 1997; Jones et al. 2006) results from inhibition or absence of RNase III cleavage in the altered rpos leader(s).

An additional RNase III cleavage site was mapped in vivo at position $\mathrm{G}_{-112}$ (Fig. 3A). Moreover, cleavage at this position was detectable in wild-type cells but not in the corresponding isogenic $h f q^{-}$mutant strain (Fig. 3A). As the absence of Hfq is known to impair efficient interactions of ncRNAs with their targets (Gottesman 2005), these data
A

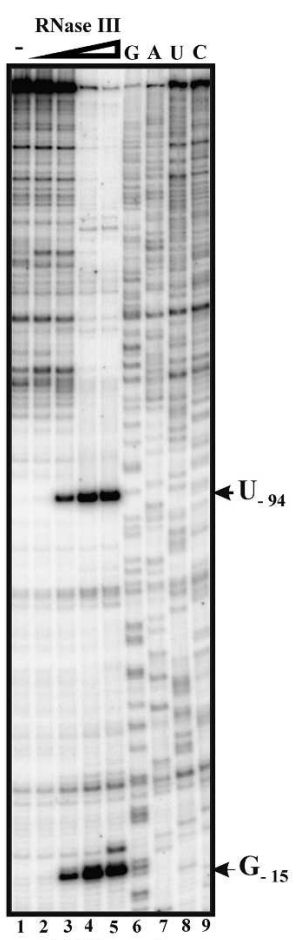

$(-) \operatorname{Dsr} A$
B

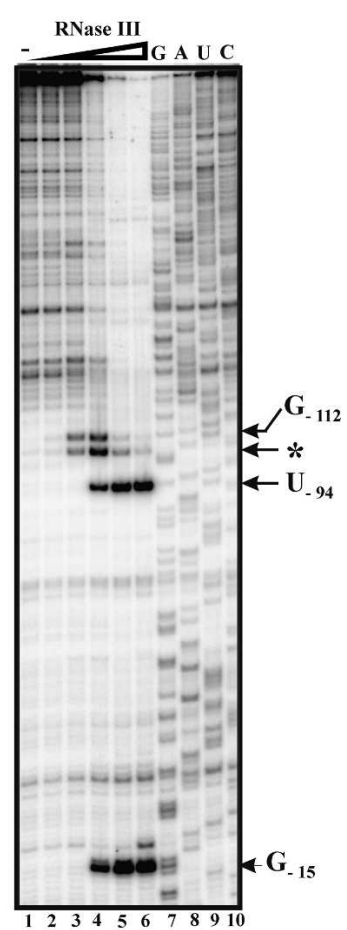

$(+)$ DsrA

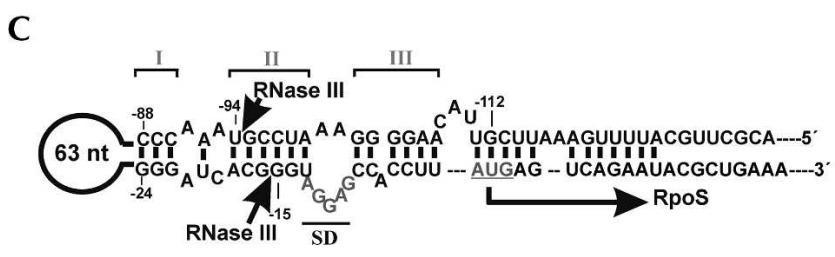

FIGURE 2. RNase III cleaves within the rpoS leader in vitro. In vitro transcribed RpoSII RNA (nucleotides -564 to +161 ) was incubated alone (lane 1) or with increasing quantities of RNase III (lanes 2-6) in the $(A)$ absence or $(B)$ presence of DsrA. The resulting products of cleavage were further analyzed by primer extension. $(C)$ The RNA sequence of a segment of the rpoS $5^{\prime}$-leader is schematically depicted at the bottom. The elements of the inhibitory stem-loop structure (stems I, II, and III) and the ribosome-binding site (underlined) are indicated. The positions of DsrA-independent (-15/-94) and DsrAdependent $\left(-112 /^{*}\right)$ RNase III cleavage were determined using a concurrently run RNA sequencing ladder (lanes 7-10) and are indicated by arrows.

suggested that RNase III cleavage at $\mathrm{G}_{-112}$ could result from rpoS interactions with small ncRNAs, for example, DsrA or RprA (Repoila et al. 2003). For verification, we compared the in vitro cleavage pattern generated by incubation of RpoSI RNA (nucleotides -146 to +55 of rpoS mRNA) with RNase III in the absence and in the presence of DsrA (Fig. 2B). This experiment showed that, in addition to the cleavage signals detected within the rpoS leader (Fig. 2A, positions -15/-94), two additional cleavage DsrA-dependent cleavage signals were observed at positions $G_{-112}$ and at $A_{-106}$ (Fig. 2B), the latter of which 
A

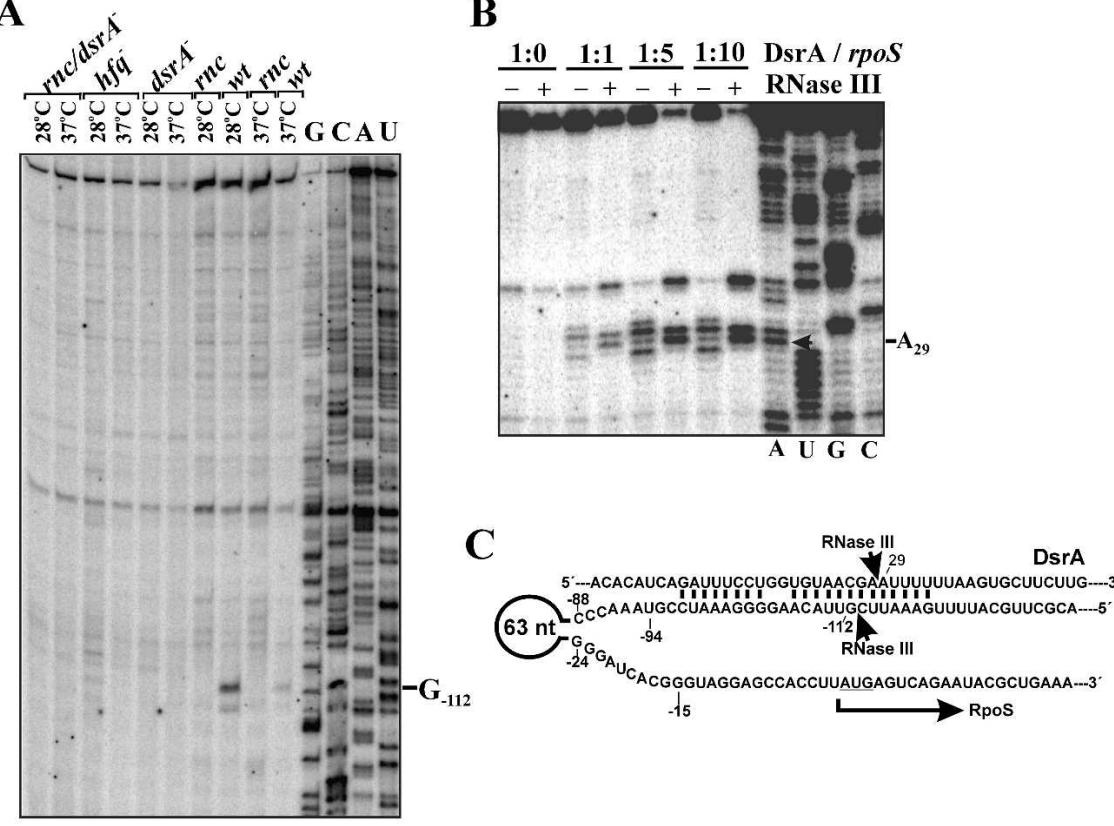

FIGURE 3. Base-pairing with DsrA induces RNase III cleavage in the rpoS $5^{\prime}$-UTR at an alternative site. (A) Primer extension analysis of total RNA isolated from the wild-type E. coli strain (wt) and isogenic RNase III (rnc), Hfq $(h f q)$, DsrA $\left(d s r A^{-}\right)$, and double $\left(r n c / d s r A^{-}\right)$ mutants grown at $28^{\circ} \mathrm{C}$ and $37^{\circ} \mathrm{C}$. The product of RNase III cleavage within the rpoS leader (position $\mathrm{G}_{-112}$ ) accumulates only in the wild-type strain. $(B)$ In vitro synthesized DsrA was incubated alone or with RNase III in the absence $(-)$ or presence $(+)$ of equimolar amount (1:1), fourfold, or ninefold molar excess of RpoSI for $10 \mathrm{~min}$ and further analyzed by primer extension. The arrow indicates the nucleotide $\left(\mathrm{A}_{28}\right)$ at which RNase III cleaves DsrA complexed with RpoSI. (C) Depicted is a part of the $r p o S / D s r A$ complex. Arrows indicate the internucleotide bonds that are cleaved by RNase III. The coordinates of nucleotides in close vicinity to the scissile bonds $\left(\mathrm{G}_{-112}\right.$ and $\left.\mathrm{A}_{29}\right)$ were determined by primer extension (see Figs. $2 \mathrm{~B}, 3 \mathrm{~B}$, respectively).

we consider to be an in vitro artifact. Taken together with the observation that the cleavage at $\mathrm{G}_{-112}$ cannot be detected in vivo in a $d s r A^{-}$strain (Fig. 3A), our data show that RNase III cleavage at this position is dependent on DsrA and occurs only upon DsrA/rpoS base-pairing.

Figure 3B shows that DsrA alone is resistant to the nucleolytic activity of RNase III. However, it is efficiently cleaved between nucleotides $\mathrm{A}_{28}$ and $\mathrm{A}_{29}$ by this endoribonuclease in the presence of increasing amounts of RpoSI RNA containing the complementary rpoS sequence (Fig. 3B). Collectively, the results of these cleavage assays (Figs. 2B and $3 \mathrm{~B})$ demonstrate that RNase III cleaves both strands of the rpoS mRNA/DsrA duplex (Fig. 3C).

\section{Alternative RNase III processing in the rpoS leader mediated by DsrA: An addition to the complex control of rpoS expression}

Here, we have provided evidence that the decay of rpoS mRNA is retarded upon inactivation of RNase III in vivo (Fig. 1) and that RNase III cleaves within the $5^{\prime}$-UTR of this transcript in vitro (Fig. 2). Apparently, in the presence of the inhibitory secondary structure, the untranslated form of the rpoS is targeted for degradation via an RNase III-dependent mechanism, which, in turn, results in low levels of rpos mRNA and diminishes $\sigma^{\mathrm{S}}$ synthesis (Fig. 4). In contrast, interactions of the rpoS 5'-UTR with DsrA and perhaps likewise with RprA not only disrupt the inhibitory secondary structure in the rpos leader but also eliminate the original RNase III cleavage site and simultaneously trigger RNase III cleavage at an alternative site within the intermediate rpoS mRNA/DsrA duplex (Fig. 4). According to the results shown in Figure $1 \mathrm{~B}$, this cleavage does not significantly affect the stability of the translationally active form of rpoS mRNA, which may be attributed to its protection from nucleases by translating ribosomes. RNase III cleavage in the DsrA/rpoS duplex (see Fig. 3) apparently prevents recycling of DsrA. This outcome is analogous to the model of coupled degradation of an ncRNA and its mRNA target (Massé et al. 2003b) and could be important for bacterial cells to avoid further up-regulation of rpoS after the stress is relieved. In summary, our findings provide new insights into the molecular mechanisms by which riboregulators activate their target mRNAs and support the idea that not only RNase E but also RNase III plays a key role in bacterial stress responses mediated by trans-encoded ncRNAs.

\section{MATERIALS AND METHODS}

\section{Bacterial strains, media, and growth conditions}

The following E. coli strains were used in this study: SDF204 (W3110 $\mathrm{rnc}^{+}$) (Dasgupta et al. 1998), SDF205 (W3110 rnc105) (Dasgupta et al. 1998), MC4100 (Tsui et al. 1994), AM111 (MC4100 $h f^{-}$) (Tsui et al. 1994), SDF204DsrA (SDF204 $\mathrm{rnc}^{+}$, dsrA1::cat), and SDF205DsrA (SDF205 rnc105, dsrA1::cat). SDF204DsrA and SDF205DsrA were constructed by P1 transduction of the dsrA1::cat mutation (Sledjeski et al. 1996) into SDF204 and SDF205 as previously described (Miller 1972). The E. coli strains were grown in Luria-Bertani (LB) medium supplemented with tetracycline $(10 \mu \mathrm{g} / \mathrm{mL})$, kanamycin $(50 \mu \mathrm{g} / \mathrm{mL})$, or chloramphenicol $(20 \mu \mathrm{g} / \mathrm{mL})$ where appropriate.

\section{In vitro transcription and $5^{\prime}$-end labeling}

RpoSI and RpoSII RNAs corresponding to E. coli rpoS mRNA nucleotides -146 to +55 and -564 to +161 , respectively, as well as 

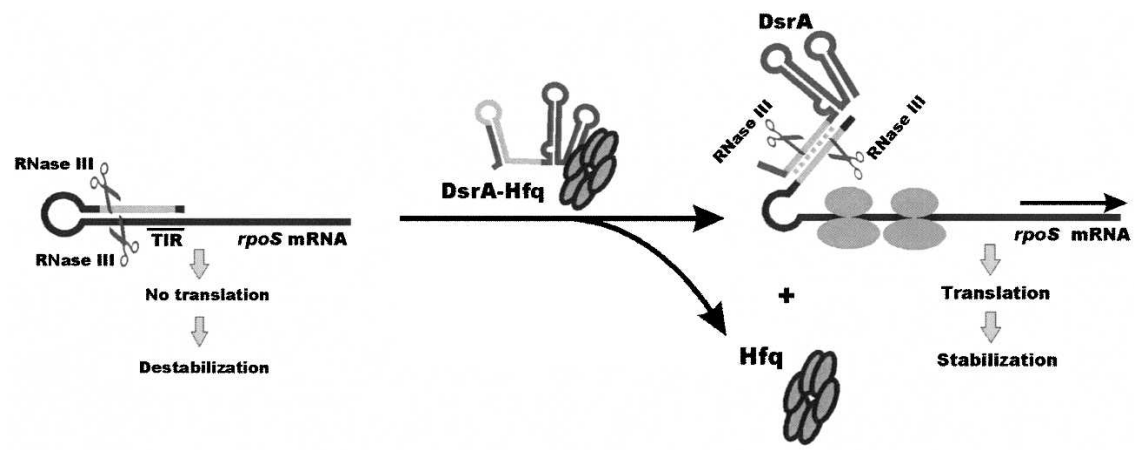

FIGURE 4. Model for post-transcriptional regulation of rpoS expression by RNase III. The translation initiation region (TIR) of the E. coli rpoS mRNA is embedded into a complex secondary structure, thereby preventing efficient ribosome binding. RNase III can cleave within the double-stranded segment of this structure, which results in destabilization of the transcript in the wild-type E. coli strain when compared to its isogenic counterpart lacking functional RNase III. In contrast to limited synthesis of RpoS under normal growth conditions, the level of RpoS is up-regulated in the presence of increasing amounts of DsrA, which accumulate at low temperature. By base-pairing with the complementary region of the rpoS leader, DsrA disrupts the inhibitory secondary structure, thereby facilitating ribosome loading and subsequent translation of RpoS (Repoila et al. 2003). DsrA/rpoS duplex formation, which is facilitated by the RNA chaperone Hfa, not only abrogates RNase III cleavage within the rpoS leader at positions $(-94 /-15)$, but also creates a new RNase III cleavage site within the DsrA/ rpoS duplex. RNase III cleavage at this site prevents reuse of DsrA for multiple cycles of rpoS activation. Moreover, the main body of the DsrA-activated rpoS mRNA is covered by translating ribosome and therefore protected from degradation by E. coli ribonucleases.

0.4). Equimolar amounts of proteins were separated on $12 \%$ SDS polyacrylamide gels, electroblotted onto Immobilon-P (Millipore), and probed with anti-RpoS antibodies (kindly provided by F. Norel, Pasteur Institute, Paris), followed by development using the ECL detection kit (Amersham).

\section{Northern blot and primer extension analysis}

E. coli strains were grown at $28^{\circ} \mathrm{C}$ or $37^{\circ} \mathrm{C}$ to early log phase $\left(\mathrm{OD}_{600}\right.$ of 0.4$)$ when rifampicin $(0.25 \mathrm{mg} / \mathrm{mL})$ was added. Total RNA was isolated from aliquots of the cultures withdrawn at various times using the hot phenol method (Lin-Chao and Bremer 1986). RNA samples ( $5 \mu \mathrm{g}$ each) were fractionated on $4 \%-8 \%$ denaturing polyacrylamide gels, transferred to Zeta-Probe membranes (BioRad) using the Trans-Blot SD Semi-Dry Transfer Cell (Bio-Rad), and then hybridized to $\left[{ }^{32} \mathrm{P}\right]$-labeled antisense RNA complementary to the E. coli rpoS mRNA (nucleotides -130 to +105$)$ according to the procedure described (Večerek et al. 2003). The DNA

DsrA were synthesized using a MEGAscript transcription kit (Ambion) and then gel-purified. The transcripts were dephosphorylated with bacterial alkaline phosphatase (MBI Fermentas), $5^{\prime}$-end-labeled with ${ }^{32} \mathrm{P}$ using $\mathrm{T} 4$ polynucleotide kinase (MBI Fermentas) together with an excess of $\left[\gamma^{-}{ }^{32} \mathrm{P}\right]$ ATP (Amersham Biosciences), and then again gel-purified as described previously (Kaberdin and Bizebard 2005). The DNA templates for transcription were generated by PCR amplification of E. coli genomic DNA using the oligonucleotide primers listed in Table 1.

\section{Western blotting}

Samples of bacterial cultures grown in $\mathrm{LB}$ medium at $28^{\circ} \mathrm{C}$ or $37^{\circ} \mathrm{C}$ were harvested in early log growth phase $\left(\mathrm{OD}_{600}\right.$ of template for in vitro synthesis of the internally labeled anti-rpoS riboprobe was generated by PCR amplification of chromosomal $E$. coli DNA with primers rSriboF and rSriboR (Table 1). The relative amount of rpoS mRNA at each time point was calculated by normalizing their signals to the 16S rRNA signal.

Primer extension analysis was performed using aliquots of total RNA $(15 \mu \mathrm{g})$ as described previously (Resch et al. 1996). Briefly, after annealing to $5^{\prime}-\left[{ }^{32} \mathrm{P}\right]$-labeled rpoS-specific oligonucleotide RpoSRT9 (or RpoSRT2) and addition of AMV-Reverse Transcriptase (Promega), cDNA synthesis was carried out for $60 \mathrm{~min}$ at $42^{\circ} \mathrm{C}$. The products of extension along with a sequencing ladder prepared using the same primer and in vitro transcribed RpoSII (nucleotides -564 to +161 ) as a template were resolved on a $6 \%$ sequencing gel, and the resulting radioactive

TABLE 1. Primers used in this study

\begin{tabular}{|c|c|c|}
\hline Name & Target gene & Sequence $\left(5^{\prime}\right.$ to $\left.3^{\prime}\right)$ \\
\hline \multicolumn{3}{|c|}{ PCR amplification of DNA templates for in vitro transcription } \\
\hline RpoSIfw & rpos & TAATACGACTCACTATAGGGAACCAGTTCAACACGCT \\
\hline RpoSIrev & rpos & CATCAAATTCCGCATCTTCAT \\
\hline RpoSIlfw & rpos & GGGCTCTAGAGTAATACGACTCACTATAGTCGGGTGAACAGAGTGCTAACAAAATGTTGCCG \\
\hline RpoSIIrev & rpos & ACACGCTGTGTGGCTCCC \\
\hline DsrAfw & $d s r A$ & GGGTCTAGACGTAATACGACTCACTATAGAACACATCAGATTTCCTGGTGTAACGAATTTTTTTAAGTG \\
\hline DsrRev & $d s r A$ & AAATCCCGACCCTGAGG \\
\hline rSriboF & rpos & TAATACGACTCACTATAGGGTTCCTGTTCTACTAAG \\
\hline rSriboR & rpos & $\overline{\text { GCTTGCATTTTGAAATTCGT }}$ \\
\hline \multicolumn{3}{|c|}{ Primer extension analysis } \\
\hline RpoSRT2 & $r p o S$ & TCCGTTCTCATCAAATTC \\
\hline RpoSRT9 & rpos & TCСGTTCTCATCAААTTСCGСАTC \\
\hline
\end{tabular}

The T7 promoter sequence is underlined. 
signals were further visualized using a PhosphorImager (Molecular Dynamics).

\section{RNase III cleavage assay}

Reaction mixtures containing 0.08 pmol of in vitro transcribed RpoSII RNA pre-hybridized with $5^{\prime}$-end $\left[{ }^{32} \mathrm{P}\right]$-labeled RpoSRT2 primer were incubated alone or with increasing amounts of RNase III (Ambion) in the absence or presence of DsrA for $10 \mathrm{~min}$ at $37^{\circ} \mathrm{C}$, and subsequently analyzed by primer extension (see Fig. 2) as described above, except that the reverse transcription was carried out for $10 \mathrm{~min}$. The RNase III cleavage assay shown in Figure 3 was performed with 100 fmol of DsrA pre-hybridized with $5^{\prime}$-end $\left[{ }^{32} \mathrm{P}\right]$-labeled primer DsrRev. After pre-incubation in $1 \times$ RNase III buffer (Ambion) for $10 \mathrm{~min}$ at $37^{\circ} \mathrm{C}$ in the presence or absence of unlabeled complementary RNAs, RNase III (Ambion) was added. Following incubation for $10 \mathrm{~min}$, aliquots were withdrawn, treated with phenol, ethanol-precipitated, and analyzed directly on $8 \%$ sequencing gels (Fig. 3B). The products of DsrA cleavage were analyzed by primer extension.

\section{ACKNOWLEDGMENTS}

This work was supported by grants F1715/F1720 (to U.B.) and F1707 (to V.R.K) from the Austrian Science Fund.

Received April 23, 2007; accepted November 9, 2007.

\section{REFERENCES}

Afonyushkin, T., Večerek, B., Moll, I., Bläsi, U., and Kaberdin, V.R. 2005. Both RNase E and RNase III control the stability of $\operatorname{sodB}$ mRNA upon translational inhibition by the small regulatory RNA RyhB. Nucleic Acids Res. 33: 1678-1689. doi: 10.1093/nar/gki313.

Agrawal, N., Dasaradhi, P.V., Mohmmed, A., Malhotra, P., Bhatnagar, R.K., and Mukherjee, S.K. 2003. RNA interference: Biology, mechanism, and applications. Microbiol. Mol. Biol. Rev. 67: 657-685.

Brown, L. and Elliott, T. 1997. Mutations that increase expression of the rpoS gene and decrease its dependence on $h f q$ function in Salmonella typhimurium. J. Bacteriol. 179: 656-662.

Dasgupta, S., Fernandez, L., Kameyama, L., Inada, T., Nakamura, Y., Pappas, A., and Court, D.L. 1998. Genetic uncoupling of the dsRNA-binding and RNA cleavage activities of the Escherichia coli endoribonuclease RNase III-The effect of dsRNA binding on gene expression. Mol. Microbiol. 28: 629-640.

Geissmann, T.A. and Touati, D. 2004. Hfq, a new chaperoning role: Binding to messenger RNA determines access for small RNA regulator. EMBO J. 23: 396-405.

Gottesman, S. 2005. Micros for microbes: Noncoding regulatory RNAs in bacteria. Trends Genet. 21: 399-404.

Hengge-Aronis, R. 2002a. Recent insights into the general stress response regulatory network in Escherichia coli. J. Mol. Microbiol. Biotechnol. 4: 341-346.

Hengge-Aronis, R. 2002b. Signal transduction and regulatory mechanisms involved in control of the $\sigma^{\mathrm{S}}$ (RpoS) subunit of RNA polymerase. Microbiol. Mol. Biol. Rev. 66: 373-395.

Huntzinger, E., Boisset, S., Saveanu, C., Benito, Y., Geissmann, T., Namane, A., Lina, G., Etienne, J., Ehresmann, B., Ehresmann, C., et al. 2005. Staphylococcus aureus RNAIII and the endoribonu- clease III coordinately regulate spa gene expression. EMBO J. 24: 824-835.

Jones, A.M., Goodwill, A., and Elliott, T. 2006. Limited role for the DsrA and RprA regulatory RNAs in rpoS regulation in Salmonella enterica. J. Bacteriol. 188: 5077-5088.

Kaberdin, V.R. and Bizebard, T. 2005. Characterization of Aquifex aeolicus RNase E/G. Biochem. Biophys. Res. Commun. 327: 382392.

Kaberdin, V.R. and Bläsi, U. 2006. Translation initiation and the fate of bacterial mRNAs. FEMS Microbiol. Rev. 30: 967-979.

Kawamoto, H., Morita, T., Shimizu, A., Inada, T., and Aiba, H. 2005. Implication of membrane localization of target mRNA in the action of a small RNA: Mechanism of post-transcriptional regulation of glucose transporter in Escherichia coli. Genes \& Dev. 19: $328-338$.

Lease, R.A. and Belfort, M. 2000. Riboregulation by DsrA RNA: Trans-actions for global economy. Mol. Microbiol. 38: 667-672.

Lease, R.A. and Woodson, S.A. 2004. Cycling of the Sm-like protein Hfq on the DsrA small regulatory RNA. J. Mol. Biol. 344: 12111223.

Lin-Chao, S. and Bremer, H. 1986. Effect of the bacterial growth rate on replication control of plasmid pBR322 in Escherichia coli. Mol. Gen. Genet. 203: 143-149.

Massé, E., Escorcia, F.E., and Gottesman, S. 2003a. Coupled degradation of a small regulatory RNA and its mRNA targets in Escherichia coli. Genes \& Dev. 17: 2374-2383.

Massé, E., Majdalani, N., and Gottesman, S. 2003b. Regulatory roles for small RNAs in bacteria. Curr. Opin. Microbiol. 6: 324.

Miller, J.H. 1972. Experiments in molecular genetics. Cold Spring Harbor Laboratory, Cold Spring Harbor, NY.

Morita, T., Maki, K., and Aiba, H. 2005. RNase E-based ribonucleoprotein complexes: Mechanical basis of mRNA destabilization mediated by bacterial noncoding RNAs. Genes \& Dev. 19: 2176 2186.

Morita, T., Mochizuki, Y., and Aiba, H. 2006. Translational repression is sufficient for gene silencing by bacterial small noncoding RNAs in the absence of mRNA destruction. Proc. Natl. Acad. Sci. 103: $4858-4863$.

Repoila, F., Majdalani, N., and Gottesman, S. 2003. Small noncoding RNAs, co-ordinators of adaptation processes in Escherichia coli: The RpoS paradigm. Mol. Microbiol. 48: 855-861.

Resch, A., Tedin, K., Grundling, A., Mundlein, A., and Blasi, U. 1996. Downstream box-anti-downstream box interactions are dispensable for translation initiation of leaderless mRNAs. EMBO J. 15: 4740-4748.

Sledjeski, D.D., Gupta, A., and Gottesman, S. 1996. The small RNA, DsrA, is essential for the low temperature expression of RpoS during exponential growth in Escherichia coli. EMBO J. 15: 39934000 .

Storz, G. and Hengge-Aronis, R.E. 2000. Bacterial stress responses. ASM Press, Washington, DC.

Tsui, H.C., Leung, H.C., and Winkler, M.E. 1994. Characterization of broadly pleiotropic phenotypes caused by an $h f q$ insertion mutation in Escherichia coli K-12. Mol. Microbiol. 13: 35-49.

Valentin-Hansen, P., Eriksen, M., and Udesen, C. 2004. The bacterial Sm-like protein Hfq: A key player in RNA transactions. Mol. Microbiol. 51: 1525-1533.

Vanderpool, C.K. and Gottesman, S. 2005. Noncoding RNAs at the membrane. Nat. Struct. Mol. Biol. 12: 285-286.

Večerek, B., Moll, I., Afonyushkin, T., Kaberdin, V.R., and Bläsi, U. 2003. Interaction of the RNA chaperone Hfq with mRNAs: Direct and indirect roles of Hfq in iron metabolism of Escherichia coli. Mol. Microbiol. 50: 897-909.

Vogel, J., Argaman, L., Wagner, E.G., and Altuvia, S. 2004. The small RNA IstR inhibits synthesis of an SOS-induced toxic peptide. Curr. Biol. 14: 2271-2276. 

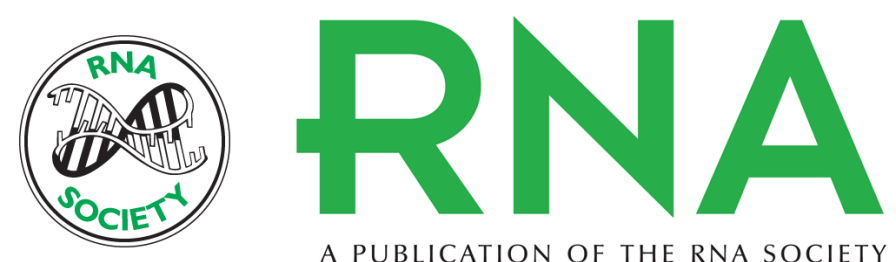

A PUBLICATION OF THE RNA SOCIETY

\section{Translational activation by the noncoding RNA DsrA involves alternative RNase III processing in the rpoS 5'-leader}

Armin Resch, Taras Afonyushkin, Tania B. Lombo, et al.

RNA 2008 14: 454-459

References This article cites 28 articles, 10 of which can be accessed free at:

http://rnajournal.cshlp.org/content/14/3/454.full.html\#ref-list-1

License

Email Alerting Receive free email alerts when new articles cite this article - sign up in the box at the Service top right corner of the article or click here. 